\title{
Impaired glucose metabolism reduces the neuroprotective action of adipocytokines in cognitively normal older adults with insulin resistance
}

\author{
Karel M. Lopez-Vilaret ${ }^{1}$, Jose L. Cantero ${ }^{1,2}$, Marina Fernandez-Alvarez ${ }^{1,2}$, Miguel Calero ${ }^{2,3}$, \\ Olga Calero ${ }^{2,3}$, Mónica Lindín ${ }^{4}$ Montserrat Zurrón4, Fernando Díaz ${ }^{4}$, Mercedes Atienza ${ }^{1,2}$ \\ ${ }^{1}$ Laboratory of Functional Neuroscience, Universidad Pablo de Olavide, Seville, Spain \\ ${ }^{2}$ CIBERNED, Network Center for Biomedical Research in Neurodegenerative Diseases, Madrid, Spain \\ ${ }^{3}$ Chronic Disease Programme, Instituto de Salud Carlos III, Madrid, Spain \\ ${ }^{4}$ Cognitive Neuroscience Laboratory, Universidade de Santiago de Compostela, Santiago de Compostela, Spain
}

Correspondence to: Mercedes Atienza; email: matirui@upo.es

Keywords: adiponectin, leptin, cognitive function, cortical thickness, metabolism

Received: July 12, $2021 \quad$ Accepted: October 26, 2021

Published: November 3, 2021

Copyright: (C) 2021 Lopez-Vilaret et al. This is an open access article distributed under the terms of the Creative Commons Attribution License (CC BY 3.0), which permits unrestricted use, distribution, and reproduction in any medium, provided the original author and source are credited.

\section{ABSTRACT}

Evidence suggests that aging-related dysfunctions of adipose tissue and metabolic disturbances increase the risk of diabetes and metabolic syndrome (MtbS), eventually leading to cognitive impairment and dementia. However, the neuroprotective role of adipocytokines in this process has not been specifically investigated. The present study aims to identify metabolic alterations that may prevent adipocytokines from exerting their neuroprotective action in normal ageing. We hypothesize that neuroprotection may occur under insulin resistance (IR) conditions as long as there are no other metabolic alterations that indirectly impair the action of adipocytokines, such as hyperglycemia. This hypothesis was tested in 239 cognitively normal older adults (149 females) aged 52 to 87 years $(67.4 \pm 5.9 \mathrm{yr})$. We assessed whether the homeostasis model assessmentestimated insulin resistance (HOMA-IR) and the presence of different components of MtbS moderated the association of plasma adipocytokines (i.e., adiponectin, leptin and the adiponectin to leptin [Ad/L] ratio) with cognitive functioning and cortical thickness. The results showed that HOMA-IR, circulating triglyceride and glucose levels moderated the neuroprotective effect of adipocytokines. In particular, elevated triglyceride levels reduced the beneficial effect of $\mathrm{Ad} / \mathrm{L}$ ratio on cognitive functioning in insulin-sensitive individuals; whereas under high IR conditions, it was elevated glucose levels that weakened the association of the Ad/L ratio with cognitive functioning and with cortical thickness of prefrontal regions. Taken together, these findings suggest that the neuroprotective action of adipocytokines is conditioned not only by whether cognitively normal older adults are insulin-sensitive or not, but also by the circulating levels of triglycerides and glucose, respectively.

\section{INTRODUCTION}

Obesity is a growing worldwide health problem that promotes cellular senescence and accelerates ageing [1]. Besides affecting physical status, obesity impacts cognitive functioning and mental health across the lifespan, leading to functional decline and reduced quality of life [2], an association that becomes mainly evident in people aged over 64 years [3].

Obesity and ageing, in addition to sharing an abnormal fat accumulation in visceral adipose depots and ectopic tissues (i.e., lipotoxicity) and progressive white adipose tissue dysfunction, induce a chronic low-grade 
inflammatory response that is partially responsible for decreased insulin sensitivity $[4,5]$. The increased adiposity associated with obesity and the redistribution of adipose tissue that occurs during ageing are accompanied by decreased adiponectin concentrations and increased leptin levels, which may reflect leptin resistance [6]. These changes in circulating adipocytokine levels also contribute to decreased insulin sensitivity by reducing their ability to activate different insulin signaling pathways [7].

Insulin, adiponectin and leptin have receptors distributed throughout the brain to support their neuroprotective function [8]. Insulin fulfills this role by regulating glutamate and GABA levels, promoting glycogen storage in astrocytes, and inhibiting neuronal necrosis and apoptosis $[9,10]$. Although the mechanisms responsible for the neuroprotective action of adiponectin and leptin remain to be elucidated, both have been implicated in improving cognitive function in normal ageing, and in reducing the incidence of cerebrovascular diseases, cognitive decline and dementia [11-20]. However, a few studies have either reported results in the opposite direction [21-24] or have found no relationship [25-27].

One possible explanation for these inconsistencies may be the study of adiponectin and leptin in isolation instead of using the balance between both of them (i.e., the $\mathrm{Ad} / \mathrm{L}$ ratio), which is considered a surrogate biomarker of adipose tissue functionality [28, 29]. This hypothesis is supported by a stronger association between the $\mathrm{Ad} / \mathrm{L}$ ratio and IR compared to that shown by adiponectin or leptin alone [30], and by studies showing that the lower the $\mathrm{Ad} / \mathrm{L}$ ratio the higher the risk of metabolic disturbances [31] and the greater the chronic low-grade inflammation [32]. To our knowledge, only a couple of studies to date have reported an association between the $\mathrm{Ad} / \mathrm{L}$ ratio and cognitive functioning in dementia-free older adults, but results again went in opposite directions $[13,24]$.

The lack of consensus regarding the relationship between circulating adipocytokines and cognitive functioning in ageing may also result from the complex communication that the adipose tissue maintains with the brain and other organs to facilitate the control of insulin and glucose [33]. Although fully functional adipose tissue is required for the maintenance of insulin sensitivity, the presence of systemic IR may reflect different degrees of dysfunction of the adipose tissue and other tissues involved in insulin signaling pathways, depending on the level of chronic low-grade inflammation and/or the concurrent presence of hyperglycemia, hypertriglyceridemia, and other metabolic disturbances typically associated with obesity, type- 2 diabetes, and MetS. Therefore, to understand the relationship between adipocytokines, brain integrity and cognitive functioning, it may be necessary to consider the potential metabolic deregulations that condition this association. We hypothesize that adipocytokines may continue to exert their neuroprotective effect under conditions of elevated HOMA-IR. However, neuroprotection may be severely diminished when glucose metabolism is deregulated, as this would indicate that adipose tissue function [34] and insulin responsiveness $[35,36]$ are increasingly impaired.

Chronic low-grade inflammation, IR, and hyperglycemia induce oxidative stress [37], which in turn has been linked to grey and white matter atrophy [38-40] and cognitive impairment [41]. Given that the prefrontal cortex becomes particularly vulnerable to the ageing process [42] and to oxidative stress during ageing [43], we also expected that the moderating influence of IR and metabolic alterations on the neuroprotective effect of adipocytokines would be manifested mainly in the prefrontal lobe, leading to changes in cortical thickness.

\section{RESULTS}

\section{Moderating role of HOMA-IR and MetS components on the adipocytokine-cognition relationship}

The hypothesis about the moderating effect of HOMAIR and different MetS components on the relationship between adipocytokines and cognitive functioning in ageing was tested in a sample of 239 cognitively unimpaired older adults. Demographic, anthropometric and metabolic measures are shown in Table 1, for the total sample and stratified by sex.

To test the above-mentioned hypothesis, we applied the frequentist approach in R [44] as well as the Bayesian approach in JASP [45]. We built 30 models as a function of the different adipocytokines (i.e., adiponectin, leptin and $\mathrm{Ad} / \mathrm{L}$ ratio), of the different MetS components (i.e., abdominal obesity, hypertension, hyperglycemia, hypertriglyceridemia, and low HDL), and according to whether only nuisance predictors were included (i.e., main effects and two-way interactions derived from the interaction between adipocytokines, HOMA-IR, and MetS component) or whether they also contained the predictor of interest (i.e., the interaction between adipocytokines, HOMAIR, and MetS component). After checking that assumptions were not violated for any statistical approach, that there were no influential cases as indicated by the residuals vs. Leverage plot, and that there were no multicollinearity problems (i.e., variable 
Table 1. Demographic, anthropometric and metabolic measures.

\begin{tabular}{lccc}
\hline & Total sample $(\mathbf{N}=\mathbf{2 3 9})$ & Females $(\mathbf{n}=\mathbf{1 4 9})$ & Males $(\mathbf{n}=\mathbf{9 0})$ \\
\hline Age (years) & $67.4 \pm 5.9$ & $66.7 \pm 6.2$ & $68.5 \pm 5.1$ \\
Education (years) & $10.2 \pm 5.2$ & $10.3 \pm 5.4$ & $10.0 \pm 4.9$ \\
BMI (kg/m ${ }^{2}$ ) & $27.5 \pm 3.8$ & $27.3 \pm 3.8$ & $27.9 \pm 3.7$ \\
Waist circumference (cm) & $91.5 \pm 11.4$ & $89.3 \pm 11.2$ & $95.0 \pm 10.8$ \\
Heart rate (ppm) & $66.2 \pm 9.9$ & $67.1 \pm 9.2$ & $64.7 \pm 11.0$ \\
CRF (ml min' $\left.{ }^{-1} \mathrm{Kg}^{-1}\right)$ & $8.1 \pm 2.2$ & $7.1 \pm 2.0$ & $9.5 \pm 1.8$ \\
Systolic blood pressure (mmHg) & $133.3 \pm 20.2$ & $132.1 \pm 19.6$ & $135.4 \pm 21.1$ \\
HDL (mmol/l) & $1.6 \pm 0.4$ & $1.6 \pm 0.4$ & $1.5 \pm 0.5$ \\
Triglycerides (mmol/l) & $1.3 \pm 0.7$ & $1.3 \pm 0.7$ & $1.3 \pm 0.6$ \\
Glucose (mmol/l) & $5.7 \pm 0.8$ & $5.6 \pm 0.7$ & $5.7 \pm 1.0$ \\
Insulin (pmol/l) & $56.0 \pm 31.0$ & $53.3 \pm 28.4$ & $60.3 \pm 34.6$ \\
HOMA-IR & $2.4 \pm 1.5$ & $2.3 \pm 1.4$ & $2.6 \pm 1.6$ \\
Adiponectin (ng/ml) & $6.6 \pm 2.2$ & $6.0 \pm 2.1$ & $7.6 \pm 2.0$ \\
Leptin (ng/ml) & $20.6 \pm 16.3$ & $25.2 \pm 15.9$ & $12.9 \pm 13.9$ \\
Ad/L ratio & $0.62 \pm 0.66$ & $0.37 \pm 0.34$ & $1.03 \pm 0.83$ \\
Metabolic syndrome components & & & \\
Abdominal obesity (no/yes) & $123 / 116$ & $86 / 63$ & $37 / 53$ \\
Hypertension (no/yes) & $86 / 153$ & $55 / 94$ & $31 / 59$ \\
Hyperglycemia (no/yes) & $111 / 128$ & $67 / 82$ & $44 / 46$ \\
Hypertriglyceridemia (no/yes) & $159 / 80$ & $98 / 51$ & $61 / 29$ \\
Low HDL (no/yes) & $175 / 64$ & $111 / 38$ & $64 / 26$ \\
Metabolic syndrome (no/yes) & $134 / 105$ & $85 / 64$ & $49 / 41$ \\
\hline
\end{tabular}

All continuous variables are expressed as mean $\pm \mathrm{SD}$. CRF, cardiorespiratory fitness.

inflation factor $<5$ ), we proceeded to determine if the contribution of the three-way interaction was over and above the contribution from the nuisance predictors.

The MetS component of interest in each model was included as categorical factor in the three-way interaction term, while all other MetS components (continuous variables) were treated as covariates together with cardiorespiratory fitness (CRF), body mass index (BMI), age, sex, years of education, adiponectin or leptin when one of them was included in the three-way interaction term, as well as the two-way interaction terms (i.e., adipocytokine $\times$ HOMA-IR; adipocytokine $\times$ MetS component; HOMA-IR $\times$ MetS component).

The ANOVAs applied to compare the null and experimental models revealed a significant three-way interaction of the $\mathrm{Ad} / \mathrm{L}$ ratio and HOMA-IR with the triglyceride $\left(\mathrm{F}_{1,222}=9.1, \mathrm{p}=0.003, \delta=2.44, \mathrm{CI}_{0.95}\right.$ [0.32 4.56]) and glucose component of MetS $\left(\mathrm{F}_{1,222}=\right.$ $\left.8.9, \mathrm{p}=0.003, \delta=-2.95, \mathrm{CI}_{0.95}[-4.83-1.09]\right)$. In the first case, the alternative hypothesis was approximately 18 times more likely than the null hypothesis $\left(\mathrm{BF}_{10}=\right.$ 17.65), and in the second case 11 times more likely $\left(\mathrm{BF}_{10}=11.11\right)$. Tables 2,3 show the estimates, $\mathrm{t}$-values and p-values for each parameter of these models. The $\mathrm{Ad} / \mathrm{L}$ ratio was positively associated with cognitive functioning for decreased levels of HOMA-IR (i.e., at 1 $\mathrm{SD}$ below the mean) if triglyceride levels were normal, and for elevated levels of HOMA-IR (i.e., at 1 SD above the mean) if glucose levels were normal. These results are illustrated in Figure 1A, 1B, respectively.

The moderating effect of Ad/L ratio, HOMA-IR and triglycerides could be attributed to leptin, because when this adipocytokine was included in the interaction term, the three-way interaction was significant $\left(\mathrm{F}_{2,221}=4.91\right.$, $\mathrm{p}=0.027$ ), although the strength of evidence was smaller than that of the $\mathrm{Ad} / \mathrm{L}$ ratio $\left(\mathrm{BF}_{10}=3.13\right)$ and the size effect was not significant $\left(\delta=-0.90, \mathrm{CI}_{0.95}[-2.25\right.$ $0.44]$ ). None of the remaining three-way interactions were significant. In all cases, the Bayesian inference revealed absence of evidence $\left(0.34<\mathrm{BF}_{10}<1.48\right)$.

\section{Moderating role of HOMA-IR and fasting blood glucose/triglycerides on the relationship between $\mathrm{Ad} / \mathrm{L}$ ratio and cortical thickness}

Having determined that the association between the $\mathrm{Ad} / \mathrm{L}$ ratio and cognitive functioning is moderated by 
Table 2. Three-way interaction between HOMA-IR, Ad/L ratio and triglycerides.

\begin{tabular}{|c|c|c|c|c|c|c|}
\hline \multirow{2}{*}{ Predictors } & \multicolumn{3}{|c|}{ Model 1} & \multicolumn{3}{|c|}{ Model 2} \\
\hline & Estimate & $t$ & $p$ & Estimate & $t$ & $p$ \\
\hline Intercept & 2.62 & 2.20 & 0.029 & 2.46 & 2.10 & 0.037 \\
\hline HOMA-IR & 0.02 & 0.20 & 0.844 & -0.01 & -0.09 & 0.928 \\
\hline $\mathrm{Ad} / \mathrm{L}$ ratio & 0.01 & 0.10 & 0.919 & -0.07 & -0.73 & 0.468 \\
\hline Triglycerides & -0.14 & -1.08 & 0.280 & -0.13 & -1.02 & 0.310 \\
\hline Glucose & -0.002 & -0.46 & 0.646 & -0.002 & -0.46 & 0.650 \\
\hline Systolic blood pressure & 0.003 & 0.94 & 0.347 & 0.004 & 1.15 & 0.250 \\
\hline HDL & -0.01 & -1.84 & 0.067 & -0.01 & -1.68 & 0.095 \\
\hline Waist circumference & 0.01 & 0.79 & 0.431 & 0.01 & 1.12 & 0.266 \\
\hline Cardiorespiratory fitness & 0.003 & 0.07 & 0.941 & 0.01 & 0.24 & 0.808 \\
\hline Body mass index & -0.02 & -0.86 & 0.389 & -0.04 & -1.30 & 0.196 \\
\hline Age & -0.05 & -4.52 & $<.001$ & -0.05 & -4.56 & $<.001$ \\
\hline Sex & 0.32 & 2.05 & 0.042 & 0.32 & 2.05 & 0.042 \\
\hline Education (years) & 0.07 & 5.81 & $<.001$ & 0.07 & 5.88 & $<.001$ \\
\hline HOMA-IR*Ad/L & -0.04 & -0.43 & 0.671 & -0.32 & -2.47 & 0.014 \\
\hline HOMA-IR*Triglycerides & 0.01 & 0.09 & 0.925 & 0.08 & 0.66 & 0.512 \\
\hline Ad/L*Triglycerides & -0.02 & -0.15 & 0.878 & 0.03 & 0.27 & 0.785 \\
\hline HOMA-IR*Ad/L*Triglycerides & & & & 0.53 & 3.02 & 0.003 \\
\hline Observations & & 239 & & & 239 & \\
\hline Min-max residuals & & -2.814 .59 & & & -2.544 .49 & \\
\hline $\mathrm{R}^{2}$ & & 0.28 & & & 0.31 & \\
\hline Adjusted $\mathrm{R}^{2}$ & & 0.24 & & & 0.26 & \\
\hline Residual Std. Error & & 0.87 & & & 0.86 & \\
\hline F Statistic & & 5.90 & & & 6.30 & \\
\hline
\end{tabular}

HOMA-IR and by glucose and triglyceride levels, we wanted to assess whether these predictors also moderated the association of $\mathrm{Ad} / \mathrm{L}$ with cortical thickness.

The ANCOVA based on frequentist inference revealed that the interaction between HOMA-IR and serum glucose levels moderated the association of the $\mathrm{Ad} / \mathrm{L}$ ratio with cortical thickness in the left lateral orbitofrontal cortex $\left(\mathrm{R}^{2}=0.04, \mathrm{~F}_{\max }=97.76, \mathrm{p}_{\text {cluster-corrected }}=0.03, \delta=\right.$ $\left.2.15 \mathrm{CI}_{0.95}[0.493 .80]\right)$ and the right rostral anterior cingulate cortex $\left(\mathrm{R}^{2}=0.06, \mathrm{~F}_{\max }=7.02\right.$, $\mathrm{p}_{\text {cluster-corrected }}=$ $\left.0.04, \delta=3.66 \mathrm{CI}_{0.95}[2.035 .30]\right)$. Indeed, the evidence was very strong in the left lateral orbitofrontal cortex $\left(\mathrm{BF}_{10}=69.37\right)$ and extreme in the right anterior cingulate $\left(\mathrm{BF}_{10}=178.12\right)$. These results are illustrated in Figure 2A. The positive association of the $\mathrm{Ad} / \mathrm{L}$ ratio with cortical thickness in the right rostral anterior cingulate cortex was evident for elevated HOMA-IR values as long as participants were normoglycemic (Figure 2B). The assessment of the three-way interaction between $\mathrm{Ad} / \mathrm{L}$, HOMA-IR and triglycerides on cortical thickness did not yield significant results.

\section{Relationship between adipocytokines-related changes in cortical thickness and cognitive functioning}

The $\mathrm{Ad} / \mathrm{L}$ ratio moderated the relationship between thickness in the right rostral anterior cingulate cortex and cognitive functioning. The ANOVA applied to compare the interactive and additive model showed a significant two-way interaction $\left(\mathrm{R}^{2}=0.32, \mathrm{~F}_{2,224}=8.16, \mathrm{p}=0.005\right)$. In particular, cortical thickness in the right anterior cingulate cortex was more positively associated with cognition at $1 \mathrm{SD}$ above the mean of the $\mathrm{Ad} / \mathrm{L}$ ratio than at $1 \mathrm{SD}$ below the mean $\left(\rho=0.72 \mathrm{CI}_{0.95}[0.181 .24]\right)$. The Bayesian analysis provided moderate evidence for the alternative hypothesis $\left(\mathrm{BF}_{10}=6.43\right)$. 
Table 3. Three-way interaction between HOMA-IR, Ad/L ratio and fasting glucose.

\begin{tabular}{|c|c|c|c|c|c|c|}
\hline \multirow{2}{*}{ Predictors } & \multicolumn{3}{|c|}{ Model 1} & \multicolumn{3}{|c|}{ Model 2} \\
\hline & Estimate & $t$ & $p$ & Estimate & $t$ & $p$ \\
\hline Intercept & 2.43 & 2.20 & 0.029 & 2.29 & 2.11 & 0.036 \\
\hline HOMA-IR & -0.10 & -0.81 & 0.421 & -0.19 & -1.55 & 0.122 \\
\hline $\mathrm{Ad} / \mathrm{L}$ ratio & -0.003 & -0.02 & 0.981 & 0.24 & 1.71 & 0.090 \\
\hline Glucose & 0.24 & 1.89 & 0.061 & 0.30 & 2.39 & 0.018 \\
\hline Triglycerides & -0.001 & -0.74 & 0.459 & -0.001 & -0.86 & 0.391 \\
\hline Systolic blood pressure & 0.003 & 1.07 & 0.284 & 0.003 & 0.99 & 0.323 \\
\hline HDL & -0.01 & -2.17 & 0.031 & -0.01 & -1.93 & 0.055 \\
\hline Waist circumference & 0.01 & 0.77 & 0.441 & 0.01 & 0.85 & 0.398 \\
\hline Cardiorespiratory fitness & 0.005 & 0.16 & 0.877 & 0.01 & 0.19 & 0.850 \\
\hline Body mass index & -0.03 & -0.99 & 0.325 & -0.02 & -0.92 & 0.359 \\
\hline Age & -0.05 & -4.60 & $<.001$ & -0.05 & -4.75 & $<.001$ \\
\hline Sex & 0.35 & 2.26 & 0.025 & 0.35 & 2.26 & 0.025 \\
\hline Education (years) & 0.07 & 5.87 & $<.001$ & 0.07 & 5.98 & $<.001$ \\
\hline HOMA-IR*Ad/L & -0.04 & -0.34 & 0.735 & 0.44 & 2.32 & 0.021 \\
\hline HOMA-IR*Glucose & 0.09 & 0.63 & 0.527 & 0.14 & 0.97 & 0.334 \\
\hline $\mathrm{Ad} / \mathrm{L} *$ Glucose & -0.004 & -0.03 & 0.978 & -0.21 & -1.40 & 0.163 \\
\hline HOMA-IR*Ad/L*Glucose & & & & -0.67 & -2.99 & 0.003 \\
\hline Observations & & 239 & & & 239 & \\
\hline Min-max residuals & & -2.934 .54 & & & -2.574 .50 & \\
\hline $\mathrm{R}^{2}$ & & 0.29 & & & 0.32 & \\
\hline Adjusted $\mathrm{R}^{2}$ & & 0.24 & & & 0.27 & \\
\hline Residual Std. Error & & 0.87 & & & 0.85 & \\
\hline F Statistic & & 6.15 & & & 6.53 & \\
\hline
\end{tabular}

\section{DISCUSSION}

The main objective of this study was to determine whether IR assessed by HOMA-IR together with other metabolic alterations associated with obesity, type-2 diabetes and MetS moderated the hypothesized neuroprotective action of adipocytokines in cognitively normal older adults. Our results suggest that the neuroprotective effect of adipocytokines is conditioned not only by the severity of IR but also by glucose and triglyceride metabolism. In particular, the results indicated that the $\mathrm{Ad} / \mathrm{L}$ ratio is associated with better cognitive functioning and increased thickness of regions in the prefrontal cortex under conditions of elevated HOMA-IR, provided that glucose metabolism is under control. Although insulinsensitive participants also benefited from adipocytokines at the cognitive level, this effect disappeared in those with hypertriglyceridemia.
Hypertriglyceridemia reduces the neuroprotective action of the $\mathrm{Ad} / \mathrm{L}$ ratio under high insulin sensitivity conditions

Among the main causes of elevated triglycerides in individuals with insulin sensitivity are obesity and adipose tissue dysfunction through mechanisms including chronic low-grade inflammation, increased lipolysis and altered adipocytokine production [33]. Our results suggest that hypertriglyceridemia reduces the cognitive benefit of adipocytokines in older adults without cognitive impairment and with high insulin sensitivity. Given that hypertriglyceridemia is recognized as an independent risk factor for atherosclerotic cardiovascular disease [46], one could think of vascular damage as a possible cause of the reduced beneficial effect of adipocytokines on cognitive functioning in ageing. Contrary to this hypothesis, fasting triglyceride levels were found to be inversely associated with 
executive function in non-demented community dwelling older adults, even after controlling for vascular risk factors such as LDL cholesterol, total cholesterol, ApoE4 status and cerebrovascular injury revealed by white matter microstructure damage [47].

Alternatively, the undesirable effect of triglycerides on the positive association between the $\mathrm{Ad} / \mathrm{L}$ ratio and cognition could be due to their ability to penetrate the blood-brain barrier (BBB) and induce central leptin and insulin receptor resistance [48], two phenomena increasingly associated with ageing-related cognitive decline and Alzheimer's disease (AD) [10, 49, 50]. There is also the possibility that elevated triglyceride levels are suggestive of increased chronic low-grade inflammation [51], which in turn can cause damage of the BBB [52] and neuroinflammation that ultimately leads to impaired cognitive function [53]. As neuroinflammation can occur with varying degrees of severity [54], it is possible that the associated functional damage may not end in neuronal death due to the neuroprotective action of insulin and adipocytokines. Although highly speculative, it could explain the lack of relationship between triglyceride levels and cortical thickness in the present study.

\section{Hyperglycemia reduces the neuroprotective action of the $A d / L$ ratio under IR conditions}

During the progression of IR, insulin fails to suppress hepatic glucose production, but paradoxically accelerates lipid synthesis, leading to hyperglycemia and hypertriglyceridemia [55]. However, a subgroup of our participants showed elevated HOMA-IR together with normal blood glucose levels. In these individuals, insulin could inhibit hepatic gluconeogenesis by acting

\section{A Normotriglyceridemia}
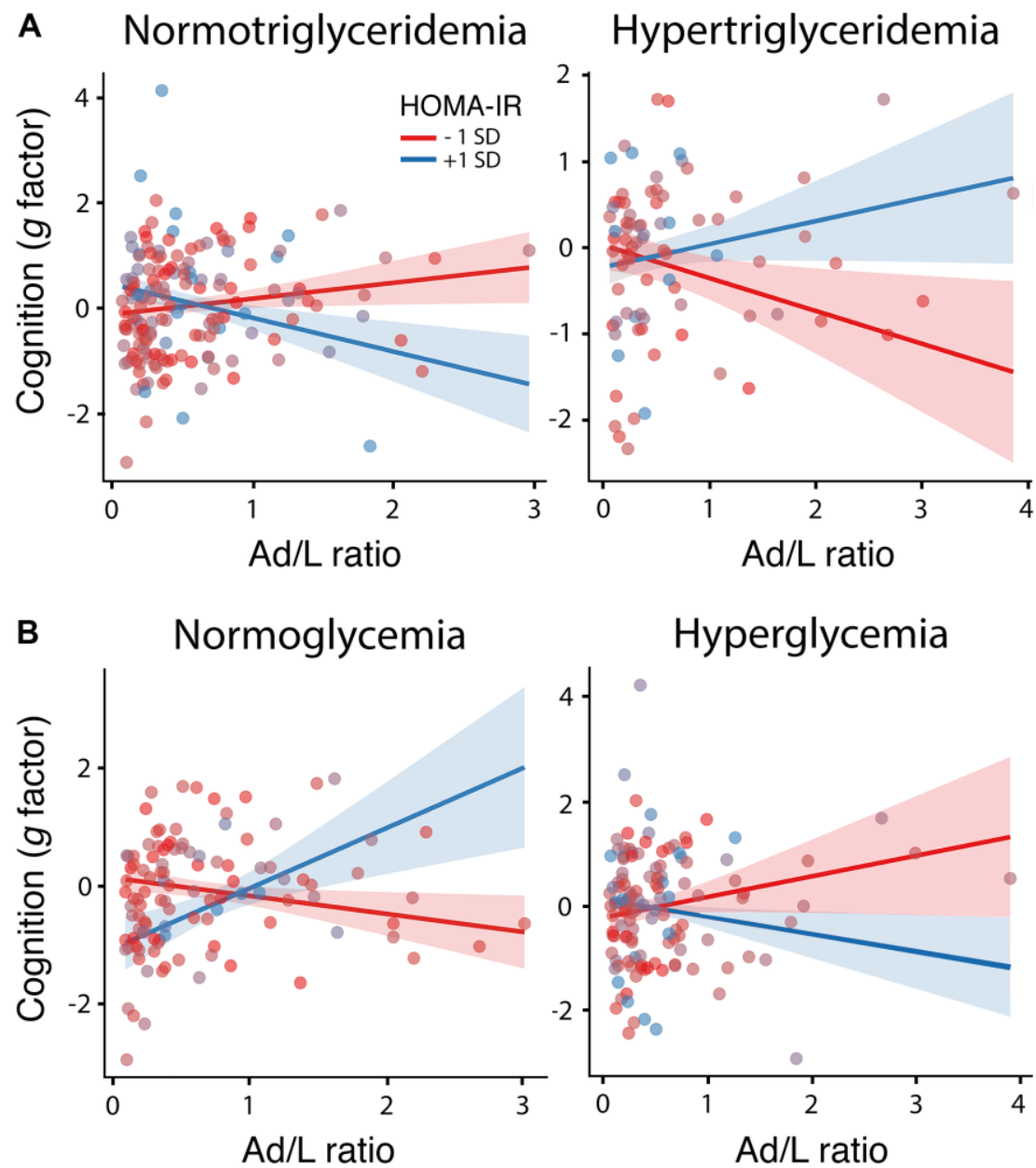

Figure 1. Moderating role of HOMA-IR, triglyceridemia and glycemia in the association between the Ad/L ratio and cognition. Association of the Ad/L ratio with cognition at 1 SD below and above the mean of HOMA-IR for participants showing normal levels of triglycerides (left panel) and hypertriglyceridemia (right panel) (A) or normal blood glucose levels (left panel) and hyperglycemia (right panel) (B) after adjustment of the remaining MtbS components, CRF, BMI, age, sex and years of education. The shaded areas reflect the confidence intervals $(95 \%)$ for the fitted values. 
directly in the liver or indirectly via the pancreas, adipose tissue and/or the brain [56]. Therefore, as long as any of these insulin-signaling pathways remain unaltered, glucose levels will remain low.

Our results suggest that the balance between adiponectin and leptin may exert its neuroprotective action also under IR conditions as long as blood glucose levels remain normal. However, when glucose metabolism is disturbed, by the progression of IR among other factors, the neuroprotective effect of adipocytokines disappears, likely due to decreased glucose uptake by astrocytes, reduced energy supply to neurons, and/or increased neuroinflammation [57].

Our findings reinforce evidence linking diabetes and prediabetes with cognitive impairment [58-61], and go a step further by suggesting that this association may be mediated by the beneficial action of adipocytokines on the structural integrity of the prefrontal cortex, in particular the rostral anterior cingulate cortex (rACC) in the right hemisphere. This finding has important implications for cognitive ageing. Firstly, because the rACC is densely connected to other areas of the prefrontal cortex,

A
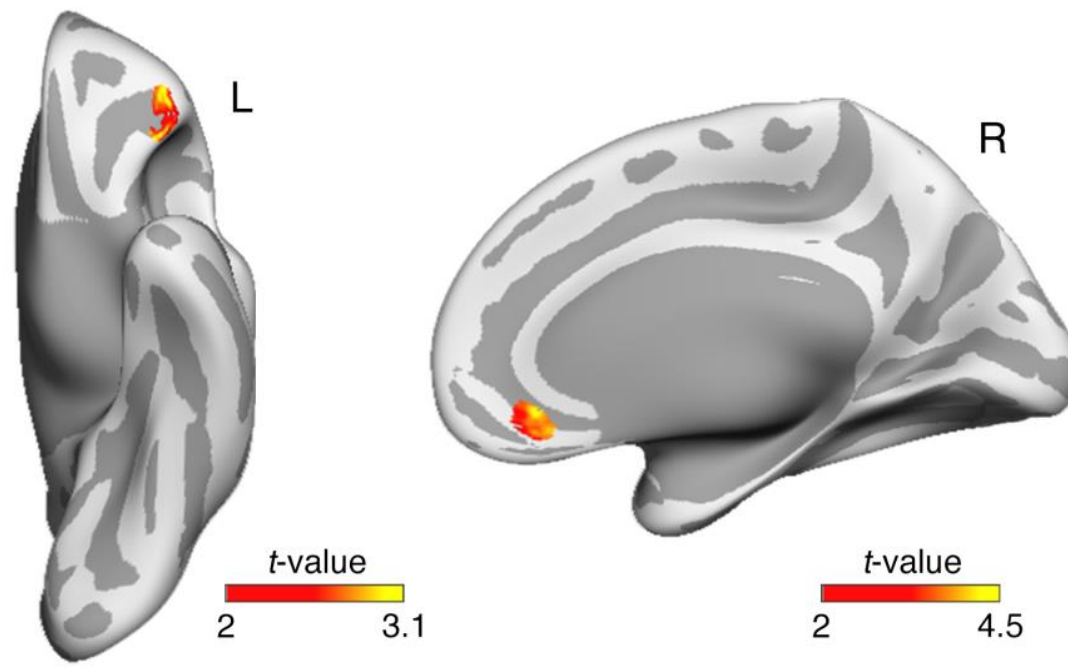

B

Normoglycemia

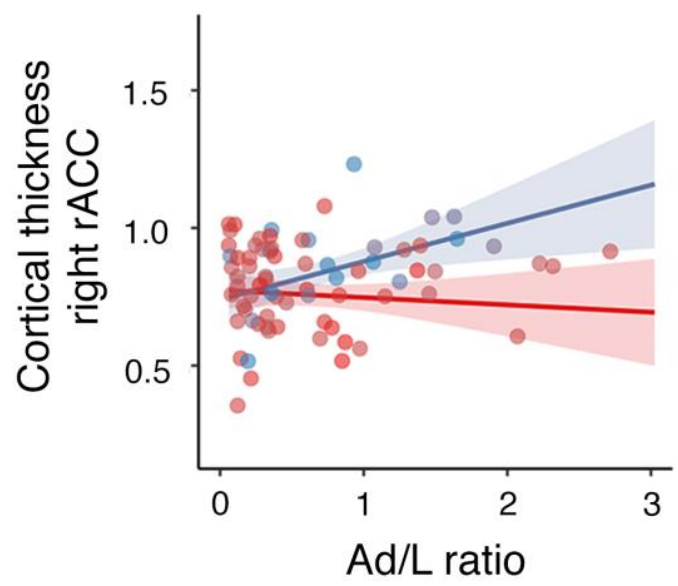

Hyperglycemia

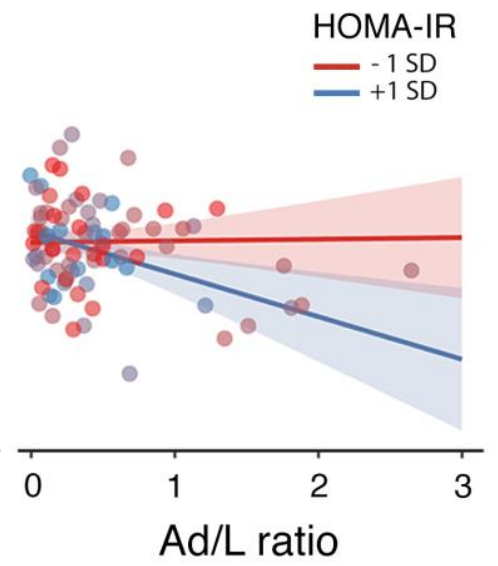

Figure 2. Moderating role of HOMA-IR and glycemia in the association between the Ad/L ratio and cortical thickness. (A) Results of the three-way interaction (Ad/L ratio $\times$ HOMA-IR $\times$ glycemia) after adjustment for the remaining MtbS components, CRF, BMI, age, sex and years of education. Significant t statistic values were projected into the inflated cortical surfaces (L: left; R: right). (B) Scatterplot to represent the post-hoc of the three-way interaction effect shown in panel (A). It shows the association of the Ad/L ratio with cortical thickness in the rostral anterior cingulate ( $\mathrm{AACC}$ ) of the right hemisphere at 1 SD below and above the mean of HOMA-IR for participants showing normal blood glucose levels (left panel) and hyperglycemia (right panel). The shaded areas reflect the confidence intervals (95\%) for the fitted values. 
making it suitable for carrying information across functional brain modules associated with social behavior, decision making, learning, attention and working memory [62]; and secondly, because ageing has shown to greatly affect the structural [63] and functional integrity of the rACC [64], which likely explains its central role in age-related cognitive decline [65]. On the basis of these results, we hypothesize that preserving functionality of adipose tissue could contribute to the success of cognitive ageing through the neuroprotective action of its adipocytokines on the rACC.

Modifiable lifestyle choices, such as increasing physical activity, eating healthy food, improving sleep quality, or decreasing stress appear to be the best approaches to prevent adipose tissue dysfunction [53]. However, once the adipose tissue becomes highly dysfunctional, therapeutic interventions with leptin and adiponectin may be more effective. Leptin replacement therapy has shown to have beneficial effects on the brain of patients with congenital leptin deficiency due to a mutation in the leptin gene. Its administration led to an increase in grey matter concentration in the ACC [66]. These effects were maintained for 3 years of supplementation, but reversed after a few weeks of withdrawal [67]. Leptin deficiency is also observed in anorexia nervosa and it is associated with the plethora of psychopathological, cognitive and sleep disturbances that characterize these patients. This symptomatology improved after exogenous administration of a recombinant human leptin for up to 14 days [68]. Additionally, low leptin levels could partially drive cognitive impairment in $\mathrm{AD}$, not only by its action on neuronal growth and function but also by its ability to inhibit amyloidogenic pathways and reduce tau phosphorylation [57]. However, it is not yet known whether leptin therapy is able to produce a clinically relevant reduction in cognitive decline in patients diagnosed with mild cognitive impairment or $\mathrm{AD}$.

The neuroprotective effect of adiponectin, on the other hand, is more likely to occur through its antiinflammatory and insulin sensitizing roles in the brain and the periphery [69]. Recent evidence from a mouse model of amyloidosis treated with adiponectin revealed its efficacy in overcoming hippocampal synaptic disturbances and inhibiting neuronal apoptosis and inflammation [70]. Given the difficulties in producing biologically active adiponectin, lifestyle interventions and the administration of adiponectin receptor agonists and drugs capable of increasing their circulating levels are a promising alternative [71]. In this vein, leptin replacement has shown to normalize adiponectin concentrations in leptin deficient ob/ob mice, with the consequent reductions in systemic oxidative stress and inflammation [32].

\section{Absence of evidence for the moderating role of the remaining MtbS components on the neuroprotective action of adipocytokines}

The present study does not allow us to draw strong conclusions about the impact of the remaining MtbS components on the neuroprotective action of adipocytokines because the range of Bayes factors was very close to 1 , which is considered anecdotal evidence according to Lee and Wagenmakers' classification scheme [72]. In the particular case of abdominal obesity, its potential effect could be due to associated metabolic disturbances, which were included as confounding variables. A similar explanation could apply to HDL cholesterol, as triglycerides largely determine plasma levels of this lipoprotein [73]. The lack of evidence regarding the impact of hypertension is not surprising considering the inconsistencies linking hypertension to cognitive dysfunction and cognitive decline [74]. The effect of hypertension could also be masked by parallel changes affecting the $\mathrm{Ad} / \mathrm{L}$ ratio, as there is evidence that both low levels of adiponectin [75] and high levels of leptin [76] may act as mediators in the development of obesity-associated hypertension.

\section{Limitations}

Our study is subject to several limitations that warrant further consideration. Due to the cross-sectional nature of the study, it is challenging to derive causal relationships. Additionally, although all participants were cognitively normal, we cannot rule out that some of them had significant levels of AD neuropathology, especially in view of the existing associations between systemic IR and increased levels of amyloid- $\beta 42$ in cerebrospinal fluid [77]. The study was further limited by the lack of a broader neuropsychological battery that included a comprehensive assessment of memory and other cognitive domains. This would not only have allowed us to assess the moderating effect of IR and other metabolic alterations on each of these cognitive domains separately, but it would also have contributed to clarify the lack of relationship between adiponectin and cognitive functioning [27]. Unfortunately, sample size and multicollinearity did not allow us to assess whether the three-way interaction was further moderated by sex and/or BMI status. Finally, we did not control for possible effects that other hormones (e.g., pancreatic, neurohypophysial and adenohypophysial among others) may have exerted on the moderating role of glycemia and triglyceridemia in the neuroprotective action of adipocytokines. All these aspects should be specifically addressed in future studies. 


\section{CONCLUSIONS}

The results derived from the present study suggest that the balance between adiponectin and leptin may be neuroprotective in ageing, although this effect is conditioned by the insulin status and other metabolic alterations. In particular, we showed that neuroprotection disappears under conditions of high insulin sensitivity when triglyceride levels are elevated. Whereas in conditions of high IR, elevated circulating glucose levels are the main limiting factor. Although the mechanisms behind these relationships need to be elucidated, results indicated that a target for the neuroprotective action of these adipocytokines, at least under conditions of IR, may be the rACC, a cortical hub linking cerebral areas governing emotion and cognitive control highly affected by ageing. Future research is required to determine whether glucose uptake as well as functional and structural connectivity patterns of this ventromedial prefrontal area are also associated with adipose tissue dysfunction, and whether interventions based either on modifiable lifestyle factors or exogenous administration of adipocytokines or drugs able to change their circulating levels improve cognition in ageing through their actions on the rACC.

\section{MATERIALS AND METHODS}

\section{Participants}

This cross-sectional study included 239 participants (52 to 87 years, mean \pm SD: $67.4 \pm 5.9,149$ females) recruited from senior citizens associations, health screening programs, and Primary Care Health Centers in Seville and Santiago de Compostela. Participants were enrolled between September 2017 and November 2019 regardless of whether or not they presented obesity, type-2 diabetes, and/or MtbS provided that they were cognitively and neurologically normal. All of them underwent neurological and neuropsychological assessments to discard objective cognitive impairment and early signs of dementia. Participants showed normal cognitive performance in the neuropsychological tests relative to appropriate reference values for age and education level, a global score of 0 in the Clinical Dementia Rating, scores $\geq 27$ in the Mini Mental State Examination, and normal independent function according to the Spanish version of the Interview for Deterioration in Daily Living Activities [78]. Participants taking drugs known to affect cognition or with a history of psychiatric illnesses, addiction disorders, or severe medical conditions such as coronary heart disease, stroke, sleep apnea, infectious disease, or cancer were excluded. The presence of depression was ruled out by the shorter version of the
Geriatric Depression Scale (scores $\leq$ 5) [79]. All participants gave informed consent to the experimental protocol approved by the Ethical Committee for Clinical Research of the Junta de Andalucía and by the Galician Clinical Research Ethics Committee (CEIC) according to the principles outlined in the Declaration of Helsinki as revised in 2008.

\section{Cognitive assessment}

All participants were administered the shortened version of the Boston Naming Test (BNT); the semantic and letter verbal fluency tests based on the "Animal" and letter "P" naming tasks; and the two forms of the Trail Making Test (TMT-A and TMT-B). All scores were $z$ transformed. In the case of TMT-A and TMT-B, we used the inverse $z$-values. Principal component analysis was applied to obtain the Spearman's ' $g$ ' factor as an index of global cognitive function. The analysis revealed two significant factors $\left(\chi^{2}=140.5, \mathrm{p}<0.001\right)$. We only retained the first one (eigenvalue 1.98), which explained $39.68 \%$ of variance in the data, due to the contribution of phonological fluency (0.79), semantic fluency (0.64), TMTA-A (0.52) and TMT-B (0.66). The second factor (eigenvalue 1.14), which explained $22.8 \%$ of variance, was not considered because it was mainly due to the contribution of BNT (0.86) and TMT-A (0.61). We used the standardized residuals to obtain the latent variable $g$ (factor loading TMT-A: 0.81; TMT-B: 0.80 ; phonological fluency: 0.58 ; semantic fluency: 0.55; BNT: 0.23).

\section{Anthropometric, resting heart rate and blood pressure}

Anthropometric examination included three body size measurements: height, weight, and waist circumference. Waist circumference was measured in standing position with non-elastic tape at the middle between the upper point of the bilateral iliac crest and the inferior margin of the rib cage in the horizontal plane at the end of expiration. The BMI was calculated by dividing weight in kilograms by the square of height in meters.

Heart rate and systolic/diastolic blood pressure measurements were obtained in sitting position, after spending $10 \mathrm{~min}$ in a quiet room maintained at a constant temperature of $22^{\circ} \mathrm{C}$.

\section{Determination of cardiorespiratory fitness (CRF)}

To avoid the burden of exercise testing, we used a low-risk, low-cost, non-exercise estimate of CRF initially conducted in a cohort mainly integrated by men [80] and later validated in three different cohorts 
aged 20 to 70 years [81] as well as in a sample of adults aged 60 to 80 years [82]. The equation-derived estimate of CRF is based on sex, age, BMI, resting heart rate, and self-reported physical activity. The self-reported physical activity was determined from a single exercise history question in which participants were asked to identify one of five physical activity categories that reflect their usual pattern of daily physical activity [81]. CRF, expressed in $\mathrm{ml} \mathrm{min}^{-1} \mathrm{~kg}^{-}$ 1 , is derived from the following equation:

$\mathrm{CRF}=\operatorname{Sex} \times 2.77-$ Age $\times 0.1-\mathrm{BMI} \times 0.17-$ heart rate $\times 0.03+$ self-reported physical activity +18.07

\section{Biochemical determinations}

Participants were instructed to fast for 12 hours prior to the blood collection appointment. One technician called them the evening before as a reminder. Upon arrival at the laboratory, they were asked about the time they had ingested their last food or drink. Fasting blood samples were taken at 9:00-10:00 AM in all participants to control for potential circadian effects. Serum levels of glucose, total cholesterol, LDL cholesterol, HDL cholesterol, and triglycerides were obtained with the automated A15 Random Access Analyzer ${ }^{\circledR}$ (Biosystems S.A., Barcelona, Spain) using Biosystems reagents. Serum insulin levels were determined with Quantikine ELISA kits (R\&D Systems, Minneapolis, MN, USA) following the manufacturer's instructions. Adiponectin and leptin levels were measured in plasma samples with Luminex human bead-based assays (BioTechne R\&D Systems) using a Luminex platform (BioPlex 200, Bio-Rad, Hercules, California, USA), according to manufacturer's instructions. For all determinations, samples, calibrators, and controls were analyzed in duplicates, and mean values were used for statistical purposes.

HOMA-IR was calculated by dividing the product of fasting serum insulin $(\mathrm{mU} / \mathrm{l})$ and glucose $(\mathrm{mmol} / \mathrm{l})$ by 22.5. SI units for insulin were transformed to conventional units by dividing by a factor of 6 .

\section{Definition of MtbS components}

The different components of MtbS were included in the interaction term as categorical factors based on the different cut-offs established by the harmonized definition where 3 of the 5 risk factors are present [83]: abdominal obesity (waist circumference $\geq 94$ and $\geq 80 \mathrm{~cm}$ for European men and women, respectively), hypertriglyceridemia $(\geq 1.7 \mathrm{mmol} / \mathrm{l})$, reduced $\mathrm{HDL}$ cholesterol $(<1.03 \mathrm{mmol} / \mathrm{l}$ in men and $<1.29 \mathrm{mmol} / \mathrm{l}$ in women), hypertension (systolic $\geq 130 \mathrm{mmHg}$ and/or diastolic $\geq 85 \mathrm{mmHg}$ ), and hyperglycemia $(\geq 5.6$ mmol/l or previously diagnosed type-2 diabetes). Drug treatments for hypertension, type- 2 diabetes, and dyslipidemia were also considered as fulfilled criteria.

\section{MRI acquisition and cortical thickness estimation}

Structural brain images were acquired on a Philips Ingenia 3T MRI scanner equipped with a 32-channel head coil (Philips, Best, Netherlands). A whole-brain T1-weighted magnetization prepared rapid gradient echo was acquired in the sagittal plane using the following parameters: repetition time $=2600 \mathrm{~ms}$, echo time $=4.7 \mathrm{~ms}$, flip angle $=9^{\circ}$, matrix $=$ $384 \times 384$, voxel resolution $=0.65 \mathrm{~mm}^{3}$ isotropic, and no gap between slices. Head motion was minimized by using a head restraint system and by placing foam padding around the subject's head. Participants were provided with headphones and foam earplugs to attenuate scanner noise.

Structural MRI data was processed using the pipeline of Freesurfer v6.0 (https://surfer.nmr.mgh.harvard.edu/) that involves intensity normalization, registration to Talairach, skull stripping, segmentation of cerebrospinal fluid, grey matter and white matter, tessellation of the white matter boundary, and automatic correction of topological defects. Pial surface misplacements and erroneous white matter segmentation was manually corrected on a slice-by-slice basis by one experienced technician to enhance the reliability of cortical thickness measurements, and then supervised by a senior researcher (JLC). Cortical thickness was defined as the average of the shortest distance between the pial surface and the grey matter-white matter boundary at each vertex across the cortical mantle.

\section{Statistical analysis}

\section{Cognition}

Before proceeding with multiple regression analyses, we applied the Yeo-Johnson transformation to the cognitive index derived from the latent variable $g$ to reduce harmful effects of skewedness and heteroscedasticity on the model [84]. Secondly, the variables included in the interaction term were mean centered and transformed to $z$ scores. Thirdly, for each one of the models we checked the linearity of the data, homogeneity of variance, and normality of residuals by inspecting the residuals vs. fitted plot, the spread-location plot, and the normal probability plot of residuals, respectively. We next tested multicollinearity through the variable inflation factor. We considered it acceptable if this value was below 5. And finally, we ruled out the presence of influential cases by examining the residuals vs. Leverage plot. 
To evaluate whether the association between adipocytokines and cognition was moderated by the relationship between HOMA-IR and the different MetS components, we built two models, one that included the main effects and the two-way interactions between the three predictors of interest (null model) and another that further included the three-way interaction (experimental model). First, we applied the frequentist approach because it remains the dominant paradigm, and then we applied the Bayesian approach to overcome the problem of multiple comparisons and quantify the evidence for both the null and the alternative hypothesis [85]. For the former approach, we computed F-tests between the two-way and three-way interaction models; while for the latter, we compared the strength of the Bayes factor for the two-way interaction model versus the model adding the three-way interaction. We used the classification scheme proposed by Lee and Wagenmakers [72] to interpret the Bayes factor.

After inferential evidence of a main effect, we computed the standardized measure of effect size (Cohen's $\mathrm{f}^{2}$ ), which allows determining the local effect size within the context of a multivariate regression model. As the interaction terms included at least one continuous moderator, we computed the standardized effect size $(\delta)$ by dividing the conditional effect at $1 \mathrm{SD}$ below and above the mean of the moderator by the root square of the mean square residual. Values of $0.4,1.0$, and 1.6 were considered "small", "medium", and "large" differences, respectively [86]. Finally, to establish the precision of effect sizes, we computed $95 \%$ confidence intervals $\left(\mathrm{CI}_{0.95}\right)$ using the normal approximated interval with bootstrapped bias and standard error through the function bootci implemented in Matlab.

\section{Cortical thickness}

Individual cortical thickness maps were Box-Cox transformed to minimize undesirable effects such as non-additivity, non-normality and heteroscedasticity [87]. Box-Cox transformed individual cortical thickness maps were further smoothed using nonlinear spherical wavelet-based de-noising schemes, which have previously shown greater specificity and sensitivity than Gaussian spatial filters for detecting local and global changes in cortical thickness [88].

The same model yielding significant results on cognition was applied to identify the influence of three-way interaction terms on cortical thickness. Results were corrected for multiple comparisons using a hierarchical statistical model that first controls the family-wise error rate at the level of clusters by applying random field theory over smoothed statistical maps $\left(\mathrm{p}_{\text {vertex }}<0.001, \mathrm{p}_{\text {cluster }}<0.05\right)$, and next controls the false discovery rate at the level of vertex within each cluster $(\mathrm{p}<0.05)$ over unsmoothed statistical maps [89].

Next, we obtained for each subject Box-Cox transformed cortical thickness values for the vertex showing the maximum $\mathrm{T}$ statistic within each significant cluster to estimate the standardized effect size. Results derived from the interaction model were visualized at $1 \mathrm{SD}$ below and above the mean of the continuous moderator. This information was additionally used to assess the relationship between cortical thickness and cognition in isolation and in interaction with the $\mathrm{Ad} / \mathrm{L}$ ratio. As the two variables of the interaction term were continuous, we computed the standardized effect size $(\rho)$ by applying the approach suggested in [86] for moderated linear associations. Bodner and colleagues proposed that values of $0.14,0.42$, and 0.71 could be considered "small", "medium", and "large" differences, respectively.

\section{Abbreviations}

AD: Alzheimer's disease; Ad/L: adiponectin to leptin ratio; $\mathrm{BBB}$ : blood brain barrier; $\mathrm{BMI}$ : body mass index; BNT: Boston naming test; $\mathrm{CI}_{0.95}=95 \%$ confidence intervals; CRF: cardiorespiratory fitness; HOMA-IR: homeostasis model assessment-estimated insulin resistance; IR: insulin resistance; MetS: metabolic syndrome; rACC: rostral anterior cingulate cortex; TMT-A/TMT-B: trail making test (form A and form B).

\section{AUTHOR CONTRIBUTIONS}

MA conceived the study and wrote the first draft. JLC, MA, ML, MZ, and FD contributed to the recruitment of study participants. KLV, MFA, MA, JLC, MC, and OC supported the data analysis. All authors contributed to data interpretation and discussion of results, revised the article for important intellectual content, and approved the final version of the manuscript.

\section{ACKNOWLEDGMENTS}

The authors thank the research staff and laboratory technicians for assistance with recruitment, screening, recording and evaluation of the participants.

\section{CONFLICTS OF INTEREST}

The authors declare that they have no conflicts of interest. 


\section{FUNDING}

This work was supported by the Spanish Ministry of Economy and Competitiveness (PSI2017-85311-P to M.A., PSI2017-89389-C2-2-R to F.D., PID2020118825GB-I00 to M.A., PID2020-119978RB-I00 to J.L.C.), CIBERNED (CB06/05/1111 to J.L.C.), the International Center on Aging CENIE-POCTEP (0348_CIE_6_E to M.A.), the Research Program for a Long-Life Society (0551_PSL_6_E to J.L.C.), the Junta de Andalucía (PY20_00858 to J.L.C.), the AndalucíaFEDER Program (UPO-1380913 to J.L.C.), and the Galician Government (ED431-2017/27 to F.D.) with ERDF/FEDER funds.

\section{REFERENCES}

1. Salvestrini V, Sell C, Lorenzini A. Obesity May Accelerate the Aging Process. Front Endocrinol (Lausanne). 2019; 10:266.

https://doi.org/10.3389/fendo.2019.00266 PMID:31130916

2. Avila C, Holloway AC, Hahn MK, Morrison KM, Restivo M, Anglin R, Taylor VH. An Overview of Links Between Obesity and Mental Health. Curr Obes Rep. 2015; 4:303-10.

https://doi.org/10.1007/s13679-015-0164-9

PMID:26627487

3. Busutil R, Espallardo O, Torres A, Martínez-Galdeano L, Zozaya N, Hidalgo-Vega Á. The impact of obesity on health-related quality of life in Spain. Health Qual Life Outcomes. 2017; 15:197.

https://doi.org/10.1186/s12955-017-0773-y

PMID:29017494

4. Pérez LM, Pareja-Galeano $H$, Sanchis-Gomar $F$, Emanuele E, Lucia A, Gálvez BG. 'Adipaging': ageing and obesity share biological hallmarks related to a dysfunctional adipose tissue. J Physiol. 2016; 594:3187-207.

https://doi.org/10.1113/JP271691 PMID:26926488

5. Spinelli $R$, Parrillo L, Longo $M$, Florese $P$, Desiderio $A$, Zatterale F, Miele C, Raciti GA, Beguinot F. Molecular basis of ageing in chronic metabolic diseases. J Endocrinol Invest. 2020; 43:1373-89.

https://doi.org/10.1007/s40618-020-01255-z

PMID:32358737

6. Izquierdo AG, Crujeiras AB, Casanueva FF, Carreira MC. Leptin, Obesity, and Leptin Resistance: Where Are We 25 Years Later? Nutrients. 2019; 11:2704. https://doi.org/10.3390/nu11112704 PMID:31717265

7. Yadav A, Kataria MA, Saini V, Yadav A. Role of leptin and adiponectin in insulin resistance. Clin Chim Acta. 2013; 417:80-84. https://doi.org/10.1016/i.cca.2012.12.007 PMID:23266767

8. Harvey J. Leptin: a diverse regulator of neuronal function. J Neurochem. 2007; 100:307-13. https://doi.org/10.1111/j.1471-4159.2006.04205.x PMID:17076761

9. Yu LY, Pei Y. Insulin neuroprotection and the mechanisms. Chin Med J (Engl). 2015; 128:976-81. https://doi.org/10.4103/0366-6999.154323 PMID:25836621

10. Spinelli M, Fusco S, Grassi C. Brain Insulin Resistance and Hippocampal Plasticity: Mechanisms and Biomarkers of Cognitive Decline. Front Neurosci. 2019; 13:788.

https://doi.org/10.3389/fnins.2019.00788 PMID: $\underline{1417349}$

11. Holden KF, Lindquist $K$, Tylavsky FA, Rosano $C$, Harris TB, Yaffe $K$, and Health ABC study. Serum leptin level and cognition in the elderly: Findings from the Health ABC Study. Neurobiol Aging. 2009; 30:1483-89. https://doi.org/10.1016/j.neurobiolaging.2007.11.024 PMID: $\underline{18358569}$

12. Lieb W, Beiser AS, Vasan RS, Tan ZS, Au R, Harris TB, Roubenoff R, Auerbach S, DeCarli C, Wolf PA, Seshadri $\mathrm{S}$. Association of plasma leptin levels with incident Alzheimer disease and MRI measures of brain aging. JAMA. 2009; 302:2565-72.

https://doi.org/10.1001/jama.2009.1836 PMID:20009056

13. Zeki Al Hazzouri A, Haan MN, Whitmer RA, Yaffe K, Neuhaus J. Central obesity, leptin and cognitive decline: the Sacramento Area Latino Study on Aging. Dement Geriatr Cogn Disord. 2012; 33:400-409. https://doi.org/10.1159/000339957 PMID:22814127

14. Yang $Y$, Hu W, Jiang $S$, Wang $B, L i Y$, Fan C, Di S, Ma Z, Lau WB, Qu Y. The emerging role of adiponectin in cerebrovascular and neurodegenerative diseases. Biochim Biophys Acta. 2015; 1852:1887-94. https://doi.org/10.1016/i.bbadis.2015.06.019 PMID:26118345

15. De Franciscis $P$, Barbieri M, Leo $S$, Dalise AM, Sardu C, Marfella R, Colacurci N, Paolisso G, Rizzo MR. Serum adiponectin levels are associated with worse cognitive function in postmenopausal women. PLoS One. 2017; 12:e0186205.

https://doi.org/10.1371/journal.pone.0186205 PMID:29267309

16. Bloemer J, Pinky PD, Govindarajulu M, Hong H, Judd R, Amin RH, Moore $T$, Dhanasekaran $M$, Reed MN, Suppiramaniam V. Role of Adiponectin in Central Nervous System Disorders. Neural Plast. 2018; 2018:4593530. 
https://doi.org/10.1155/2018/4593530

PMID:30150999

17. Cezaretto A, Suemoto CK, Bensenor I, Lotufo PA, de Almeida-Pititto B, Ferreira SR, and ELSA Research Group. Association of adiponectin with cognitive function precedes overt diabetes in the Brazilian Longitudinal Study of Adult Health: ELSA. Diabetol Metab Syndr. 2018; 10:54.

https://doi.org/10.1186/s13098-018-0354-1

PMID:30002734

18. Yin H, Tian S, Huang R, Cai R, Guo D, Lin H, Wang J, Wang S. Low Plasma Leptin and High Soluble Leptin Receptor Levels Are Associated With Mild Cognitive Impairment in Type 2 Diabetic Patients. Front Aging Neurosci. 2018; 10:132.

https://doi.org/10.3389/fnagi.2018.00132

PMID:29867443

19. Letra L, Matafome $P$, Rodrigues $T$, Duro D, Lemos R, Baldeiras I, Patrício M, Castelo-Branco M, Caetano G, Seiça R, Santana I. Association between Adipokines and Biomarkers of Alzheimer's Disease: A Cross-Sectional Study. J Alzheimers Dis. 2019; 67:725-35. https://doi.org/10.3233/JAD-180669 PMID:30689587

20. van Andel M, van Schoor NM, Korten NC, Comijs HC, Heijboer AC, Drent ML. The Association Between HighMolecular-Weight Adiponectin, Ghrelin and Leptin and Age-Related Cognitive Decline: Results From Longitudinal Aging Study Amsterdam. J Gerontol A Biol Sci Med Sci. 2021; 76:131-40.

https://doi.org/10.1093/gerona/glaa126

PMID:32447377

21. Gunstad J, Spitznagel MB, Keary TA, Glickman E, Alexander T, Karrer J, Stanek K, Reese L, JuvancicHeltzel J. Serum leptin levels are associated with cognitive function in older adults. Brain Res. 2008; 1230:233-36.

https://doi.org/10.1016/i.brainres.2008.07.045

PMID: 18675793

22. Gustafson DR, Mielke MM, Keating SA, Holman S, Minkoff H, Crystal HA. Leptin, Adiponectin and Cognition in Middle-aged HIV-infected and Uninfected Women. The Brooklyn Women's Interagency HIV Study. J Gerontol Geriatr Res. 2015; 4:240.

https://doi.org/10.4172/2167-7182.1000240 PMID:27536467

23. Sanz B, Arrieta H, Hervás G, Rezola-Pardo C, Ruiz-Litago F, Iturburu M, Gil SM, Rodríguez-Larrad A, Irazusta J. Serum adiponectin is associated with body composition and cognitive and psychological status in older adults living in long-term nursing homes. Exp Gerontol. 2019; 121:1-9.

https://doi.org/10.1016/i.exger.2019.03.005

PMID: $\underline{30885718}$
24. Feinkohl I, Janke J, Slooter AJ, Winterer G, Spies C, Pischon T. Plasma leptin, but not adiponectin, is associated with cognitive impairment in older adults. Psychoneuroendocrinology. 2020; 120:104783. https://doi.org/10.1016/j.psyneuen.2020.104783 PMID:32623019

25. Teixeira AL, Diniz BS, Campos AC, Miranda AS, Rocha NP, Talib LL, Gattaz WF, Forlenza OV. Decreased levels of circulating adiponectin in mild cognitive impairment and Alzheimer's disease. Neuromolecular Med. 2013; 15:115-21.

https://doi.org/10.1007/s12017-012-8201-2 PMID:23055000

26. Gilbert T, Roche S, Blond E, Bar JY, Drai J, Cuerq C, Haution-Bitker M, Ecochard R, Bonnefoy $M$. Association between Peripheral Leptin and Adiponectin Levels and Cognitive Decline in Patients with Neurocognitive Disorders $\geq 65$ Years. J Alzheimers Dis. 2018; 66:1255-64.

https://doi.org/10.3233/JAD-180533

PMID: 30400097

27. Magalhães CA, Ferreira CN, Loures CM, Fraga VG, Chaves AC, Oliveira AC, de Souza LC, Resende EP, Carmona KC, Guimarães HC, Cintra MT, Lanna IN, Zauli DA, et al. Leptin, hsCRP, TNF- $\alpha$ and IL- 6 levels from normal aging to dementia: Relationship with cognitive and functional status. J Clin Neurosci. 2018; 56:150-55. https://doi.org/10.1016/j.jocn.2018.08.027 PMID:30150062

28. Frühbeck G, Catalán V, Rodríguez A, Gómez-Ambrosi J. Adiponectin-leptin ratio: A promising index to estimate adipose tissue dysfunction. Relation with obesityassociated cardiometabolic risk. Adipocyte. 2018; 7:57-62. https://doi.org/10.1080/21623945.2017.1402151 PMID:29205099

29. Frühbeck G, Catalán V, Rodríguez A, Ramírez B, Becerril S, Salvador J, Colina I, Gómez-Ambrosi J. Adiponectinleptin Ratio is a Functional Biomarker of Adipose Tissue Inflammation. Nutrients. 2019; 11:454.

https://doi.org/10.3390/nu11020454

PMID:30813240

30. Inoue $M$, Yano M, Yamakado M, Maehata E, Suzuki S. Relationship between the adiponectin-leptin ratio and parameters of insulin resistance in subjects without hyperglycemia. Metabolism. 2006; 55:1248-54.

https://doi.org/10.1016/i.metabol.2006.05.010 PMID: 16919546

31. Vega GL, Grundy SM. Metabolic risk susceptibility in men is partially related to adiponectin/leptin ratio. J Obes. 2013; 2013:409679.

https://doi.org/10.1155/2013/409679

PMID:23533722 
32. Frühbeck $G$, Catalán $\mathrm{V}$, Rodríguez $\mathrm{A}$, Ramírez $\mathrm{B}$, Becerril $S$, Portincasa P, Gómez-Ambrosi J. Normalization of adiponectin concentrations by leptin replacement in ob/ob mice is accompanied by reductions in systemic oxidative stress and inflammation. Sci Rep. 2017; 7:2752.

https://doi.org/10.1038/s41598-017-02848-0

PMID:28584304

33. Stern JH, Rutkowski JM, Scherer PE. Adiponectin, Leptin, and Fatty Acids in the Maintenance of Metabolic Homeostasis through Adipose Tissue Crosstalk. Cell Metab. 2016; 23:770-84.

https://doi.org/10.1016/i.cmet.2016.04.011

PMID:27166942

34. van de Woestijne AP, Monajemi $H$, Kalkhoven $E$, Visseren FL. Adipose tissue dysfunction and hypertriglyceridemia: mechanisms and management. Obes Rev. 2011; 12:829-40.

https://doi.org/10.1111/i.1467-789X.2011.00900.x PMID:21749607

35. Martyn JA, Kaneki M, Yasuhara S. Obesity-induced insulin resistance and hyperglycemia: etiologic factors and molecular mechanisms. Anesthesiology. 2008; 109:137-48.

https://doi.org/10.1097/ALN.0b013e3181799d45

PMID:18580184

36. Ma M, Liu H, Yu J, He S, Li P, Ma C, Zhang $H$, Xu L, Ping $F$, Li W, Sun $Q$, Li Y. Triglyceride is independently correlated with insulin resistance and islet beta cell function: a study in population with different glucose and lipid metabolism states. Lipids Health Dis. 2020; 19:121.

https://doi.org/10.1186/s12944-020-01303-w PMID: $\underline{32487177}$

37. Etchegoyen M, Nobile MH, Baez F, Posesorski B, González J, Lago N, Milei J, Otero-Losada M. Metabolic Syndrome and Neuroprotection. Front Neurosci. 2018; 12:196.

https://doi.org/10.3389/fnins.2018.00196

PMID:29731703

38. Klosinski LP, Yao J, Yin F, Fonteh AN, Harrington MG, Christensen TA, Trushina E, Brinton RD. White Matter Lipids as a Ketogenic Fuel Supply in Aging Female Brain: Implications for Alzheimer's Disease. EBioMedicine. 2015; 2:1888-904.

https://doi.org/10.1016/j.ebiom.2015.11.002

PMID:26844268

39. Scheff SW, Ansari MA, Mufson EJ. Oxidative stress and hippocampal synaptic protein levels in elderly cognitively intact individuals with Alzheimer's disease pathology. Neurobiol Aging. 2016; 42:1-12.

https://doi.org/10.1016/j.neurobiolaging.2016.02.030 PMID:27143416
40. Peña-Bautista C, López-Cuevas R, Cuevas A, Baquero $\mathrm{M}$, Cháfer-Pericás C. Lipid peroxidation biomarkers correlation with medial temporal atrophy in early Alzheimer Disease. Neurochem Int. 2019; 129:104519.

https://doi.org/10.1016/j.neuint.2019.104519 PMID:31398364

41. Kandlur A, Satyamoorthy K, Gangadharan G. Oxidative Stress in Cognitive and Epigenetic Aging: A Retrospective Glance. Front Mol Neurosci. 2020; 13:41. https://doi.org/10.3389/fnmol.2020.00041 PMID: $\underline{32256315}$

42. Feng $X$, Guo J, Sigmon HC, Sloan RP, Brickman AM, Provenzano FA, Small SA, and Alzheimer's Disease Neuroimaging Initiative. Brain regions vulnerable and resistant to aging without Alzheimer's disease. PLoS One. 2020; 15:e0234255.

https://doi.org/10.1371/journal.pone.0234255 PMID:32726311

43. Venkateshappa C, Harish G, Mahadevan A, Srinivas Bharath MM, Shankar SK. Elevated oxidative stress and decreased antioxidant function in the human hippocampus and frontal cortex with increasing age: implications for neurodegeneration in Alzheimer's disease. Neurochem Res. 2012; 37:1601-14. https://doi.org/10.1007/s11064-012-0755-8 PMID:22461064

44. R Core Team. R: A language and environment for statistical computing. R Foundation for Statistical Computing. 2020. https://www.R-project.org/

45. JASP Team. JASP (Version 0.12.2). 2020. https://jaspstats.org/

46. Grundy SM, Stone NJ, Bailey AL, Beam C, Birtcher KK, Blumenthal RS, Braun LT, de Ferranti $S$, FaiellaTommasino J, Forman DE, Goldberg R, Heidenreich PA, Hlatky MA, et al. 2018 AHA/ACC/AACVPR/AAPA/ABC/ ACPM/ADA/AGS/APhA/ASPC/NLA/PCNA Guideline on the Management of Blood Cholesterol: A Report of the American College of Cardiology/American Heart Association Task Force on Clinical Practice Guidelines. Circulation. 2019; 139:e1082-143.

https://doi.org/10.1161/CIR.0000000000000625 PMID: $\underline{0586774}$

47. Parthasarathy V, Frazier DT, Bettcher BM, Jastrzab L, Chao L, Reed B, Mungas D, Weiner M, DeCarli C, Chui $\mathrm{H}$, Kramer JH. Triglycerides are negatively correlated with cognitive function in nondemented aging adults. Neuropsychology. 2017; 31:682-88.

https://doi.org/10.1037/neu0000335 PMID:28604016

48. Banks WA, Farr SA, Salameh TS, Niehoff ML, Rhea EM, Morley JE, Hanson AJ, Hansen KM, Craft S. Triglycerides 
cross the blood-brain barrier and induce central leptin and insulin receptor resistance. Int J Obes (Lond). 2018; 42:391-97.

https://doi.org/10.1038/ijo.2017.231 PMID:28990588

49. McGuire MJ, Ishii M. Leptin Dysfunction and Alzheimer's Disease: Evidence from Cellular, Animal, and Human Studies. Cell Mol Neurobiol. 2016; 36:203-17.

https://doi.org/10.1007/s10571-015-0282-7 PMID:26993509

50. Forny-Germano L, De Felice FG, Vieira MN. The Role of Leptin and Adiponectin in Obesity-Associated Cognitive Decline and Alzheimer's Disease. Front Neurosci. 2019; 12:1027.

https://doi.org/10.3389/fnins.2018.01027 PMID:30692905

51. Feingold KR, Grunfeld C. The Effect of Inflammation and Infection on Lipids and Lipoproteins. 2019. In: Feingold KR, Anawalt B, Boyce A, Chrousos G, de Herder WW, Dhatariya K, Dungan K, Grossman A, Hershman JM, Hofland J, Kalra S, Kaltsas G, Koch C, Kopp $P$, Korbonits $M$, Kovacs $C S$, Kuohung $W$, Laferrère B, McGee EA, McLachlan R, Morley JE, New M, Purnell J, Sahay R, Singer F, Stratakis CA, Trence DL, Wilson DP, editors. Endotext. South Dartmouth (MA): MDText.com, Inc., 2000.

PMID:26561701

52. Rönnbäck C, Hansson E. The Importance and Control of Low-Grade Inflammation Due to Damage of Cellular Barrier Systems That May Lead to Systemic Inflammation. Front Neurol. 2019; 10:533. https://doi.org/10.3389/fneur.2019.00533 PMID:31191433

53. Atienza M, Ziontz J, Cantero JL. Low-grade inflammation in the relationship between sleep disruption, dysfunctional adiposity, and cognitive decline in aging. Sleep Med Rev. 2018; 42:171-83. https://doi.org/10.1016/i.smrv.2018.08.002 PMID:30241997

54. DiSabato DJ, Quan N, Godbout JP. Neuroinflammation: the devil is in the details. J Neurochem. 2016 (Suppl 2); 139:136-53. https://doi.org/10.1111/jnc.13607 PMID:26990767

55. Santoleri D, Titchenell PM. Resolving the Paradox of Hepatic Insulin Resistance. Cell Mol Gastroenterol Hepatol. 2019; 7:447-56. https://doi.org/10.1016/j.jcmgh.2018.10.016 PMID:30739869

56. Girard J. The Inhibitory Effects of Insulin on Hepatic Glucose Production Are Both Direct and Indirect. Diabetes. 2006 (Suppl 2); 55:S65-S69. https://doi.org/10.2337/db06-S009
57. Paz-Filho G, Wong ML, Licinio J. The procognitive effects of leptin in the brain and their clinical implications. Int J Clin Pract. 2010; 64:1808-12. https://doi.org/10.1111/i.1742-1241.2010.02536.x PMID:21070531

58. Dybjer E, Nilsson PM, Engström G, Helmer C, Nägga K. Pre-diabetes and diabetes are independently associated with adverse cognitive test results: a crosssectional, population-based study. BMC Endocr Disord. 2018; 18:91.

https://doi.org/10.1186/s12902-018-0318-3 PMID:30514382

59. Dybjer E, Engström G, Helmer C, Nägga K, Rorsman $P$, Nilsson PM. Incretin hormones, insulin, glucagon and advanced glycation end products in relation to cognitive function in older people with and without diabetes, a population-based study. Diabet Med. 2020; 37:1157-66.

https://doi.org/10.1111/dme.14267 PMID:32020688

60. Cichosz SL, Jensen MH, Hejlesen O. Cognitive impairment in elderly people with prediabetes or diabetes: A cross-sectional study of the NHANES population. Prim Care Diabetes. 2020; 14:455-59. https://doi.org/10.1016/i.pcd.2019.11.005 PMID: $\underline{31831376}$

61. Jia $Y$, Liu R, Tang S, Zhang D, Wang Y, Cong L, Hou T, Ren J, Du Y. Associations of the Glycaemic Control of Diabetes with Dementia and Physical Function in RuralDwelling Older Chinese Adults: A Population-Based Study. Clin Interv Aging. 2021; 16:1503-13. https://doi.org/10.2147/CIA.S319633 PMID:34413638

62. Tang W, Jbabdi S, Zhu Z, Cottaar M, Grisot G, Lehman JF, Yendiki A, Haber SN. A connectional hub in the rostral anterior cingulate cortex links areas of emotion and cognitive control. Elife. 2019; 8:e43761.

https://doi.org/10.7554/eLife.43761

PMID:31215864

63. Vaidya JG, Paradiso S, Boles Ponto LL, McCormick LM, Robinson RG. Aging, grey matter, and blood flow in the anterior cingulate cortex. Neuroimage. 2007; 37:1346-53.

https://doi.org/10.1016/i.neuroimage.2007.06.015 PMID:17692536

64. Cao W, Luo C, Zhu B, Zhang D, Dong L, Gong J, Gong D, He H, Tu S, Yin W, Li J, Chen H, Yao D. Resting-state functional connectivity in anterior cingulate cortex in normal aging. Front Aging Neurosci. 2014; 6:280. https://doi.org/10.3389/fnagi.2014.00280 PMID:25400578

65. Cera N, Esposito R, Cieri F, Tartaro A. Altered Cingulate Cortex Functional Connectivity in Normal Aging and 
Mild Cognitive Impairment. Front Neurosci. 2019; 13:857.

https://doi.org/10.3389/fnins.2019.00857

PMID:31572106

66. Matochik JA, London ED, Yildiz BO, Ozata M, Caglayan $\mathrm{S}$, DePaoli AM, Wong ML, Licinio J. Effect of leptin replacement on brain structure in genetically leptindeficient adults. J Clin Endocrinol Metab. 2005; 90:2851-54.

https://doi.org/10.1210/jc.2004-1979 PMID:15713712

67. London ED, Berman SM, Chakrapani S, Delibasi T, Monterosso J, Erol HK, Paz-Filho G, Wong ML, Licinio J. Short-term plasticity of gray matter associated with leptin deficiency and replacement. J Clin Endocrinol Metab. 2011; 96:E1212-20.

https://doi.org/10.1210/jc.2011-0314 PMID:21613360

68. Milos G, Antel J, Kaufmann LK, Barth N, Koller A, Tan S, Wiesing U, Hinney A, Libuda L, Wabitsch M, von Känel R, Hebebrand J. Short-term metreleptin treatment of patients with anorexia nervosa: rapid on-set of beneficial cognitive, emotional, and behavioral effects. Transl Psychiatry. 2020; 10:303.

https://doi.org/10.1038/s41398-020-00977-1

PMID:32855384

69. Ng RC, Chan KH. Potential Neuroprotective Effects of Adiponectin in Alzheimer's Disease. Int J Mol Sci. 2017; 18:592.

https://doi.org/10.3390/ijms18030592

PMID:28282917

70. Wang M, Jo J, Song J. Adiponectin improves long-term potentiation in the 5XFAD mouse brain. Sci Rep. 2019; 9:8918.

https://doi.org/10.1038/s41598-019-45509-0 PMID:31222110

71. Liu Y, Vu V, Sweeney G. Examining the Potential of Developing and Implementing Use of AdiponectinTargeted Therapeutics for Metabolic and Cardiovascular Diseases. Front Endocrinol (Lausanne). 2019; 10:842.

https://doi.org/10.3389/fendo.2019.00842 PMID:31920962

72. Lee MD, Wagenmakers EJ. Bayesian cognitive modeling: A practical course. Cambridge University Press. 2013.

73. Welty FK. How do elevated triglycerides and low HDLcholesterol affect inflammation and atherothrombosis? Curr Cardiol Rep. 2013; 15:400. https://doi.org/10.1007/s11886-013-0400-4 PMID:23881582

74. Tadic M, Cuspidi C, Hering D. Hypertension and cognitive dysfunction in elderly: blood pressure management for this global burden. BMC Cardiovasc Disord. 2016; 16:208.

https://doi.org/10.1186/s12872-016-0386-0

PMID:27809779

75. Kim DH, Kim C, Ding EL, Townsend MK, Lipsitz LA. Adiponectin levels and the risk of hypertension: a systematic review and meta-analysis. Hypertension. 2013; 62:27-32. https://doi.org/10.1161/HYPERTENSIONAHA.113.0145 3 PMID:23716587

76. Allison MA, Ix JH, Morgan C, McClelland RL, Rifkin D, Shimbo D, Criqui $\mathrm{MH}$. Higher leptin is associated with hypertension: the Multi-Ethnic Study of Atherosclerosis. J Hum Hypertens. 2013; 27:617-22. https://doi.org/10.1038/jhh.2013.24 PMID:23535989

77. Hoscheidt SM, Starks EJ, Oh JM, Zetterberg H, Blennow K, Krause RA, Gleason CE, Puglielli L, Atwood CS, Carlsson CM, Asthana S, Johnson SC, Bendlin BB. Insulin Resistance is Associated with Increased Levels of Cerebrospinal Fluid Biomarkers of Alzheimer's Disease and Reduced Memory Function in At-Risk Healthy Middle-Aged Adults. J Alzheimers Dis. 2016; 52:1373-83.

https://doi.org/10.3233/JAD-160110 PMID:27079723

78. Böhm P, Peña-Casanova J, Aguilar M, Hernández G, Sol JM, Blesa R. Clinical validity and utility of the interview for deterioration of daily living in dementia for Spanish-speaking communities NORMACODEM Group. Int Psychogeriatr. 1998; 10:261-70. https://doi.org/10.1017/s1041610298005377 PMID: 9785147

79. Yesavage JA, Brink TL, Rose TL, Lum O, Huang V, Adey $M$, Leirer VO. Development and validation of a geriatric depression screening scale: a preliminary report. J Psychiatr Res. 1982; 17:37-49. https://doi.org/10.1016/0022-3956(82)90033-4

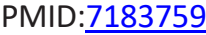

80. Jackson AS, Blair SN, Mahar MT, Wier LT, Ross RM, Stuteville JE. Prediction of functional aerobic capacity without exercise testing. Med Sci Sports Exerc. 1990; 22:863-70.

https://doi.org/10.1249/00005768-199012000-00021 PMID:2287267

81. Jurca R, Jackson AS, LaMonte MJ, Morrow JR Jr, Blair SN, Wareham NJ, Haskell WL, van Mechelen W, Church TS, Jakicic JM, Laukkanen R. Assessing cardiorespiratory fitness without performing exercise testing. Am J Prev Med. 2005; 29:185-93. https://doi.org/10.1016/i.amepre.2005.06.004 PMID:16168867

82. McAuley E, Szabo AN, Mailey EL, Erickson KI, Voss M, White SM, Wójcicki TR, Gothe N, Olson EA, Mullen SP, 
Kramer AF. Non-Exercise Estimated Cardiorespiratory Fitness: Associations with Brain Structure, Cognition, and Memory Complaints in Older Adults. Ment Health Phys Act. 2011; 4:5-11.

https://doi.org/10.1016/j.mhpa.2011.01.001

PMID:21808657

83. Alberti KG, Eckel RH, Grundy SM, Zimmet PZ, Cleeman JI, Donato KA, Fruchart JC, James WP, Loria CM, Smith SC Jr, and International Diabetes Federation Task Force on Epidemiology and Prevention, and National Heart, Lung, and Blood Institute, and American Heart Association, and World Heart Federation, and International Atherosclerosis Society, and International Association for the Study of Obesity. Circulation. 2009; 120:1640-45.

https://doi.org/10.1161/CIRCULATIONAHA.109.192644 PMID:19805654

84. Yeo IK, Johnson RA. A new family of power transformations to improve normality or symmetry. Biometrika. 2000; 87: 954-59.

https://doi.org/10.1093/biomet/87.4.954

85. Wagenmakers EJ, Marsman $M$, Jamil $T$, Ly $A$, Verhagen J, Love J, Selker R, Gronau QF, Šmíra M, Epskamp S, Matzke D, Rouder JN, Morey RD. Bayesian inference for psychology. Part I: Theoretical advantages and practical ramifications. Psychon Bull Rev. 2018; 25:35-57. https://doi.org/10.3758/s13423-017-1343-3

PMID:28779455
86. Box G, Cox D. An Analysis of Transformations (with Discussion). J R Stat Soc Series B Stat Methodol. 1964; 26:211-52. https://doi.org/10.1111/j.2517-6161.1964.tb00553.x

87. Bernal-Rusiel JL, Atienza M, Cantero JL. Detection of focal changes in human cortical thickness: spherical wavelets versus Gaussian smoothing. Neuroimage. 2008; 41:1278-92. https://doi.org/10.1016/i.neuroimage.2008.03.022 PMID:18474434

88. Bernal-Rusiel JL, Atienza M, Cantero JL. Determining the optimal level of smoothing in cortical thickness analysis: a hierarchical approach based on sequential statistical thresholding. Neuroimage. 2010; 52:158-71. https://doi.org/10.1016/j.neuroimage.2010.03.074 PMID:20362677

89. Bodner TE. Standardized Effect Sizes for Moderated Conditional Fixed Effects with Continuous Moderator Variables. Front Psychol. 2017; 8:562. https://doi.org/10.3389/fpsyg.2017.00562 PMID:28484404 